\title{
Consumer involvement-a vital piece of the quality quilt: the California HealthCare Foundation's strategy for engaging California consumers
}

\section{A Monroe}

How can the delivery of health services be made accountable to the needs and desires of those who receive and, ultimately, pay for them? The approach of the California HealthCare Foundation (CHCF) has been to build a supply of consumer friendly information, to encourage societal vigilance through public reporting, and to disseminate it using both traditional and non-traditional strategies in order to reach underserved and disenfranchised populations.

Correspondence to: Ms A Monroe, Director of Quality Initiative,

California HealthCare

Foundation (CHCF), 476

Ninth Street, Oakland, CA

94607, USA;

amonroe@chcf.org
$\mathrm{P}$ roviders of health services have historically not been directly accountable to consumer preferences for a number of reasons which can be described as (1) the "knowledge gap" (medicine is highly technical and impossible for the lay person to evaluate adequately); (2) the "payment gap" ( services are usually purchased on behalf of individuals by organizations such as government or employers); and (3) the "culture gap" (a collective learned willingness to defer to the authority of medical professionals or to the system itself). The understanding that such accountability cannot be simply taken for granted (as it would in a normal market place for goods and services) defines a core challenge for health care-how can the delivery of health services be made accountable to the needs and desires of those who receive and, ultimately, pay for them?

The many efforts to respond to this core challenge have given rise to a diverse set of disciplines and approaches designed to assure, measure, and improve "quality". Quality has become a patchwork quilt of considerable complexityonly when one is able to step back and view the whole do the bits and pieces assemble themselves into an aesthetic and coherent pattern. Taking a broad view, there are at least five fronts on which healthcare quality advances:

- the discovery and validation of evidence-based best practices in medicine;

- proper incentives encouraging (or at least not discouraging) providers continuously to improve their delivery of evidence-based medical care;

- appropriate systems of measurement for public reporting;

- informed engaged consumers;

- strong and sustained societal vigilance.

Of these, the first three fronts-what might be described as the utilitarian aspects of healthcare quality-seem to have received the most attention by the quality community. Measurement is, of course, crucial, but quality can quickly turn into an exclusively technical conversation that gives even technicians a sense of frustration about its progress. Since its creation in 1998 by the California HealthCare Foundation (CHCF, box 1), the Quality Initiative (QI) has funded provocative research and development activities in all of these important dimensions with particular emphasis on the last two fronts-the creation of informed engaged consumers and the encouragement of sustained societal vigilance. In so doing, it aims to strengthen those areas of the "quilt" that may be difficult to get at while avoiding duplication of other equally important efforts.

\section{WHY "CONSUMER"?}

Before describing the Quality Initiative's activities in this area, an explanation is needed of the context in which the word "consumer" is used. In our

\section{Box 1 California HealthCare Foundation}

The California HealthCare Foundation (CHCF) is a non-profit philanthropic organization based in Oakland, California. The Foundation was established in May 1996 as a result of the conversion of Blue Cross of California from a non-profit health plan to WellPoint Health Networks, a for-profit corporation. The Foundation's overall mission is "to expand access to affordable quality health care for underserved individuals and communities and to promote fundamental improvements in the health status of the people of California". With such a broad mission and limited resources, the work of the CHCF is primarily focused on three areas of the healthcare system: health care delivery, the business of health care, and health policy. Through the philanthropic strategies of grant making, data analysis, and dissemination and stimulation of informed public discourse, the $\mathrm{CHCF}$ strives to be thoughtful in contributing to better understanding of the healthcare system and practical in helping to move issues toward solutions.

The Quality Initiative serves as a catalyst to stimulate consumer use of quality of care data in making healthcare decisions and improving overall quality of care through public accountability. 
view, a consumer has agency, choice, and, most importantly, a voice in both choosing and using healthcare services. In addition to the typical consumers targeted by educational efforts, we also work to engage individuals in public programs such as Medicaid (Medi-Cal in California) which funds care for lower income populations, and Medicare which covers senior citizens. One of the goals of the Quality Initiative is to encourage all segments of beneficiaries to exhibit true consumer behavior-that is, to hold appropriate expectations of quality, to use appropriate mechanisms for "comparison shopping", to show a willingness to question and push back on caregivers, and to develop the capacity to have their complaints heard and redressed.

The Quality Initiative's approach to improving qualitywhich centers on consumer empowerment through information and the encouragement of societal vigilance-is presented, as well as the many questions that still remain unanswered in this promising field of endeavor.

\section{THE WORK OF THE QUALITY INITIATIVE Building the supply of consumer friendly information} At the outset, although we were eager to embark on an ambitious public information campaign, we realized that we needed to invest resources in building a supply of the kind of information consumers would actually find useful, based on well established validated standardized indicators of healthcare quality. Without relevant information to disseminate, we had little hope of educating, motivating, or mobilizing others to use it.

To pinpoint what kinds of information consumers find relevant, a major opinion and attitude research project was undertaken. The collaborative research project was conducted for CHCF between November 1999 and February 2000 by RAND and included both qualitative (focus groups) and quantitative (survey) data. The CHCF wanted to know how consumers in California view information about healthcare quality; what sources of information they use and trust; what motivates them to seek information about quality; and how consumers are using the Internet to find healthcare information.

The unprecedented depth of the survey, which reached 4089 adults in California, not only allowed us to draw conclusions about the average Californian but also to analyze valuable data about five vulnerable subgroups: people aged over 55 years, Spanish speaking and English speaking people (Hispanics), people with less than a high school education, and people who rate their health as fair or poor.

We discovered that:

- California consumers in this survey perceived health care to be very important and, for most people, it was the issue most likely to be rated as a big concern. However, for people who have many other economic and social pressures in their lives such as Spanish speaking and English speaking people who describe themselves as Hispanic, health and health care ranked below care of family and safety from crime.

- While a small majority of people reported no difficulty making choices about health care, a quarter reported moderate or extreme difficulty, with those in poor health having the most difficulty.

- Consumers made their choices about health and health care without the information they need. Only a third had the right kind of information all of the time and $40 \%$ had it only some or none of the time. The information deficit was greatest for people with low levels of education, those in fair or poor health, and Hispanics.

- More than a third of people who changed doctors in the 2 years before the survey reported that they found it difficult to find a new one that they liked. Over half the people in fair or poor health had difficulty.

- Consumers tended to distrust quality information that came from individual hospitals, health maintenance organizations (HMOs), or drug companies. Government agencies also ranked low on the trust scale. The most highly trusted sources of information about quality of health care were the patient's own physician, disease advocacy organizations such as the American Cancer Society, and family and friends. Internet sites were not widely trusted.

- Consumers expressed interest in a wide range of different kinds of information that would be useful to them including treatment guidelines, expert ratings, and results of consumer surveys, but would probably integrate it into their decision processes along with information they received from trusted personal sources such as doctors, friends and family, and other patients.

- There were particular times when people were most likely to seek information about health care. These "teachable moments" included:

- when choosing a health plan (when entering the work force, changing jobs or during periods of open enrollment);

- when choosing a new physician or group practice (moving to a new city, changing health plans, when a doctor retires, pregnancy, or a medical diagnosis requiring a specialist);

- when pregnant, diagnosed with a serious medical condition, or requiring a major procedure, new treatment, or medication.

Using these responses as a guide, and based on an analysis by Quality Initiative staff of the gaps in the quality information currently available to Californians, grants were made to fund the following quality performance measurement projects:

(1) Patients' Evaluation of Performance in California (PEP-C)

(2) Guide to California Medicare HMOs

(3) Translation of the Consumer Assessment of Health Plans Survey (CAHPS) into Medi-Cal threshold languages

(4) CA Nursing Home Consumer Information System

Patients' Evaluation of Performance in California (PEP-C) This project was the first meaningful scientifically valid survey of patient experience in California hospitals to be reported publicly in a statewide report. The survey questioned 21151 patients from 113 hospitals throughout California to evaluate their hospital stay using a respected instrument developed by the Picker Institute (which has since been acquired by the National Research Corporation). The instrument, which measures hospital experience from the patient perspective, had been extensively tested and validated on a nationwide sample before its use in California.

The survey focused on areas where research had shown patient experience to be a valid indicator of healthcare quality: whether patients received adequate pain relief, were treated with respect by providers, or received clear understandable instructions on how to care for themselves upon their return home.

Survey results were released publicly in August 2001. Overall, the survey found that patients believe California hospitals are doing a good job in attending to physical comfort, including pain control, but believe they could do better in easing patients' transition to home. The study also found that Californians admitted to hospital for maternity care or surgical procedures reported more positive experiences than those admitted for general medical care. The survey also showed that performance among California hospitals lagged slightly 
Box 2 Seven steps to choosing a Medicare HMO that's right for you

\section{Step 1: Find out if you are eligible}

Just because an HMO offers Medicare plans in your county doesn't mean you are always eligible. Some HMOs operate in only certain parts of a county and others may not be accepting new members. You can call the health plans or the California Health Insurance Counseling and Advocacy Program (HICAP) at 1-800-434-0222 for eligibility information.

\section{Step 2: Select the HMO network}

To make a good choice you will need to find out whether the doctors and hospitals you want to use belong to a particular HMO network. If they don't belong to any and you are reluctant to switch providers, consider staying in traditional Medicare and buying a Medicare Supplement policy, also known as a Medigap policy.

\section{Step 3: Get value for your money}

The 2002 Guide to California Medicare HMOs rates each $\mathrm{HMO}$ plan according to the generosity of the benefits it offers in relation to the premium and copayments it requires you to pay, using a scale of one to five stars. Plans with more stars provide better values for most beneficiaries.

\section{Step 4: Understand the prescription drug benefit}

Drug coverage is one of the best reasons to join a Medicare HMO, but no plan will cover all of your prescription drug expenses. To evaluate a plan's drug benefit you need to understand how a plan's formulary, copayments, annual maximum benefit, and brand name drug penalty may limit your coverage.

\section{Step 5: Note how members view the plan}

After selecting one or two plans based on premiums, benefits, and the drug benefit, check to see how members view the plan. If members are dissatisfied or a large number of providers recently left the plan, you may want to consider other options.

\section{Step 6: Consider an HMO's financial health}

The Guide provides information about each $\mathrm{HMO}^{\prime}$ s profitability and financial stability. A low rating is not a prediction that a company will go out of business, but it does indicate that financial problems may be more likely.

\section{Step 7: Consider how well the plans provide} preventive care

Much of the responsibility for quality of care rests with the medical groups, but the health plans are also responsible for some of the care delivered by doctors in their networks. Look for plans whose members are most likely to receive diagnostic tests and other important medical treatments.

behind that of hospitals nationwide. The project was notable because participation was completely voluntary and participants showed a serious commitment to improving the quality of hospital care in California. However, only 113 hospitals took part in the survey-about $30 \%$ of the 380 hospitals eligible to participate-which created substantive gaps in statewide and regional results, particularly in Southern California. A challenge for future surveys is to make the PEP-C project comprehensive and meaningful for all Californians.

The PEP-C survey will continue, with the next public report scheduled for mid 2003. This will enable Californians to monitor hospital performance over time and will show the progress of hospitals in addressing issues identified in previous surveys. In capturing the patient experience rather than other "objective" measures of quality, we intend to create a consumer friendly resource that emulates the collective advice of "family and friends". We hope to continue to build this database and to encourage more hospitals in the state to participate.

\section{Guide to California Medicare HMOs: All Medicare HMOs Are NOT Alike}

This report, the first of its kind, was developed using funding from CHCF by Consumers Union, the publisher of Consumer Reports, a well respected consumer journal, and provides objective comparable information on every Medicare HMO plan available in the 35 California counties where it is an option. The Guide rates each plan on its overall value - that is, the total benefits provided after deducting what people pay for them, and its prescription drug coverage (the proportion of all prescription drug costs a plan pays for its members). The Guide also shows how much a plan will pay for drugs used to treat diabetes, congestive heart failure, hypertension, and rheumatoid arthritis, and provides comparable information on preventive services and member satisfaction. A seven step guide to lead people through the choices they have to make to find the best HMO plan for their medical condition and financial situation is also included (box 2).

The Guide, which was published in July 2001 and again in March 2002, reached over 400000 households and was widely discussed by media and community organizations. The RAND survey found that Consumer Reports was a trusted source of comparative information. The most recent version of the Guide is available at www.chcf.org (follow link for Guide to California Medicare HMOs-Updated for 2002).

Translation of the Consumer Assessment of Health Plans Survey (CAHPS) into Medi-Cal threshold languages The survey clearly showed that the most vulnerable populations (those on low incomes and those who are non-English speaking) have the greatest need of information. Through our efforts, the CAHPS patient-reported assessments of both medical groups and HMOs are now available in Spanish, Vietnamese, Chinese, Khmer, and Korean.

\section{CA Nursing Home Consumer Information System}

This first ever public report of validated indicators of quality of skilled nursing facilities has been developed by a coalition of the University of California, San Francisco (UCSF), the University of Wisconsin, Madison, RAND, the UCLA/Borun Center for Gerontological Research, and the California Advocates for Nursing Home Reform (CANHR). It is the most comprehensive skilled nursing facility (SNF) quality information set available nationwide, developed from a combination of existing state and federal nursing home patient data, facility inspection reports, and individual nursing home characteristics.

The report will enable consumers to distinguish high quality homes from those that provide lower quality care. RAND and the UCLA/Borun Center have reviewed the indicators to ensure that they accurately measure nursing home quality.

The measures include the appearance and programs of facilities; state and federal inspection results including identified deficiencies and enforcement actions; consumer complaints filed with the state; staffing indicators including staff wages and benefits, staffing levels and turnover rates; financial indicators including facility solvency; nutrition and eating; physical and cognitive functioning; behavioral and emotional patterns; skin care; psychotropic drug use; accidents; elimination and incontinence; and quality of life. The database is complete and the work will be released to the public in September 2002. 
Encouraging societal vigilance through public reporting: the challenge of building provider consensus Public reporting of these kinds of information achieves more than the salutary long term objective of creating better ways for individuals to become more informed, self-directed, and empowered with regard to their health management. Such dissemination also activates and empowers the "influencers" - that is, the media, consumer watchdog organizations, labor leaders, employers, legislators, and other advocates-who are in a position to instigate change. Although it is important for individuals to participate in their own health care and to make informed choices between providers, we believe it is unrealistic and inappropriate to shift the burden for quality assurance fully onto individuals. There will always be medical and economic circumstances in which people simply cannot "vote with their feet" or where the choices one is offered are less than sufficient because of system wide barriers to quality improvement. The existence of a robust consumer voice in health care should not replace a broader social responsibility to set standards for medical care and to monitor against them.

Such monitoring can be conducted in a variety of ways: voluntarily by healthcare systems themselves; in response to mandates by purchasers of care such as employers; through citizen group activism; and by the Government itself. There are important advantages to each of these approaches; a balanced strategy would include a role for all four.

The challenge of getting healthcare providers to cooperate with regulatory or voluntary reporting efforts should not be underestimated. As mentioned earlier, only $30 \%$ of the state's eligible hospitals participated in the PEP-C project despite 18 months of intensive hospital recruiting, offers of free technical assistance in quality improvement efforts, the encouragement of blue ribbon endorsers, and the potential embarrassment that would seem to accompany abstention from this highly visible public rating initiative. We are hopeful that a positive public response to the release of the survey will encourage more voluntary participants this year and that provider acceptance will continue to grow until a critical mass is achieved.

Although the reality is quite a different story, we believe that, at a minimum, every organization within the healthcare sector has a responsibility to account publicly for the quality of care it provides. Americans have come to expect the news media to deliver regular quality reports such as school listings of average achievement scores of students and airline-specific safety and on-time performance. Basic information such as Health Plan Employer Data and Information Set (HEDIS) scores (box 3) regarding the medical quality of specific providers should be equally commonplace. Although we recognize that there are measurement challenges associated with smaller entities such as individual physicians or small medical practices, history has shown that nothing spurs methodological improvements faster than a requirement for public reporting.

\section{Dissemination: going beyond the obvious targets and the usual suspects}

In addition to the traditional media outreach and typical "launch" strategies, the Quality Initiative is making specific efforts to support consumer and patient organizations in being champions and allies for the cause of improving quality of care and disseminating the new information. We will be providing mini-grants for dissemination support, tool kits for consumer groups to use with their constituencies, translation of materials into multiple languages, and policy briefings for non-traditional consumer groups.

Additionally, eight diverse consumer groups, ranging from disease specific organizations such as Win Against Breast Cancer to ethnic centred programs like the California Black

\section{Box 3 HEDIS}

HEDIS is a set of standardized performance measures used in the US to ensure that purchasers and consumers have the information they need to compare the performance of managed healthcare plans reliably. The performance measures in HEDIS are related to many significant public health issues such as cancer, heart disease, smoking, asthma, and diabetes. HEDIS also includes a standardized survey of consumers' experiences that evaluates plan performance in areas such as customer service, access to care, and claims possessing. HEDIS is sponsored, supported, and maintained by the National Committee for Quality Assurance (NCQA).

Health Network, have been funded to enhance consumer and patient organization involvement in quality of care issues. These new resources, closely linked to vulnerable populations, will allow us to expand the circle of involved and committed groups and to provide sustained consumer and advocacy interest in quality concerns.

Our communications and outreach plans for PEP-C, the Comparative Medicare HMO Guide, and the Consumer Assessment place heavy emphasis on partnering with local community groups, organizations that work directly with the target populations (Medicare beneficiaries), and with disease specific organizations. The regional comparative guides will be produced in both English and Spanish to increase the accessibility of the information.

Although a growing number of people do feel empowered by the increased availability of medical information in print and on the Internet, it is far from universally available, trusted, or accurate. Our survey found that those who seek information on the Internet are more likely to be male, middle aged or younger, white, better educated, and English speaking. They are in better health but use more traditional and alternative care. By contrast, those aged over 55, people with less than a high school education, ethnic minorities (except Asian), and those whose language preference is Spanish are far less likely to turn to the Internet as a source of healthcare information.

Because of the growing availability of healthcare information on line and the concerns that have been raised about the validity of that information, the Quality Initiative recently completed a project to evaluate the accuracy and usefulness of information available through the Internet in both English and Spanish.

\section{THE CHALLENGES}

In 1992 Donabedian $^{2}$ made a persuasive case that consumers-whom he defined as "patients and those who may legitimately speak on their behalf"- should and do play key roles in assuring and enhancing quality of care. His comments regarding consumers and quality-made nearly a decade ago-not only affirm the importance of identifying and amplifying a true consumer voice in health care, but tacitly underscore the great difficulty of doing so. How is it that a concept so self-evident 10 years ago remains more the exception than the rule today?

Although US healthcare consumers-even those covered by public programs - are likely to have more choice of providers than UK "consumers", Donabedian's remarks are a reminder that a concern for the opinions and attitudes of healthcare service recipients is a core requirement of any system that wishes to define and measure the success of its efforts. But, as he further points out: "it is one thing to affirm the right and duty of every patient to define and evaluate the quality of care and quite another to give legitimate, practical expression to that belief". 
Tracking, aggregating, and publicizing consumer attitudes and opinions about health providers in a way that draws legitimate distinctions and encourages meaningful decision making is a significant challenge which, in fact, consists of three separate challenges:

- Building a supply of defensible systems of measurement and interpretation that address the kinds of comparative information consumers find useful.

- Consensus among providers for such measurement to occur and/or regulatory requirements for publicly reporting quality data.

- A dissemination strategy that reaches beyond the obvious targets and the usual suspects.

\section{CONCLUSIONS: LESSONS LEARNED AND OPEN QUESTIONS}

Important lessons for policy makers, influencers, healthcare providers, and the quality assurance community are contained in these activities and studies. Although some are obvious, we are currently soliciting proposals for an extensive independent evaluation of the effectiveness of the efforts of the Quality Initiative to leverage its resources.

We have learned that it is critical to consider both timing and context when increasing public awareness of quality considerations. People who are active and healthy are not highly motivated to dig deeply into issues about medical care, but "teachable moments" (a first pregnancy or a serious diagnosis) provoke intense information seeking behavior. Who do people go to for help? Is the appropriate information readily available?

In encouraging societal vigilance we also intend to explore new and better ways to encourage public reporting by providers and to help to coordinate such efforts so that duplication and excessive administrative expense can be avoided. We hope to achieve greater clarity on what might be the appropriate roles for government and for the private sector.

\section{Key messages}

- Consumers' perceptions of quality and the kinds of information they seek are often different from measures commonly sought by healthcare workers.

- Despite the increased availability of health care and quality information on the Internet, such information remains inaccessible to many important patient groups and is of uneven quality.

- In communicating quality information to consumers, it is important to think "out of the box" and to find trusted sources such as community organizations to help spread the word.

Finally, in reaching beyond the usual means of disseminating information we will continue to think "out of the box". What might come from a creative reconsideration of the roles played by employers, clergy, therapists, newspapers, and telephone directories in calling for and/or providing salient "just in time" healthcare information? How can we help to ensure that those groups have access to more information than disinformation?

The Quality Initiative hopes that questions such as these will continue to stimulate an enriched and expanded view of who "owns" the quality conversation and what it might be about. The quality "quilt" deserves to be strengthened and extended for the benefit of all.

\section{REFERENCES}

1 Berland GK, Elliott MN, Morales LS, et al. Health information on the Internet: accessibility, quality, and readability in English and Spanish. JAMA 2001;285:2612-21.

2 Donabedian A. Quality assurance in health care: consumers' role. Qual Health Care 1992;1:247-51. 